\title{
A Mini-Review on the Effect of Design Parameters on the Performance of Latent Heat Thermal Energy Storage
}

\author{
Sanjay Choudhary, Dinesh Kumar Sharma, Brij Mohan Sharma, Shubham Sahu \\ Department of Mechanical Engineering, Swami Keshvanand Institute of Technology, Management and \\ Gramothan, Jaipur-302017 (INDIA) \\ Email-sanjay.sahu.mech@gmail.com \\ Received 06.08.2020 received in revised form 15.10.2020, accepted 17.10.2020
}

\begin{abstract}
Efficient energy utilization is helpful to promote the use of renewable energy resources such as solar energy. The depletion and scarcity are well known issues faced with the conventional energy resources. Hence, it is need of the hour to utilize thermal energy in an efficient manner to counter these issues. Therefore, it is essential to design a thermal energy storage system which can have high energy storage density. Latent heat thermal energy storage (LHTES) is preferred choice for storing thermal energy in a compact space compared to the sensible heat thermal energy storage (SHTES). However, previous literature report various issues associated with design and development of LHTES such as low thermal conductivity of the storage materials phase change materials (PCMs), improper heat transfer, etc. Hence, it is required to use techniques to enhance the rate of heat transfer while charging /discharging of LHTES. Further, heat transfer can be increased by proper considerations of design and operational parameters. This paper summarizes the design modifications in recent years that improve the effectiveness of LHTES for various applications.
\end{abstract}

Keywords:Latent heat thermal energy storage; phase change material; triplex tube heat exchanger.

\section{INTRODUCTION}

Energy is the backbone in the economic prosperity of any nation. Energy demands are increasing in every sector day by day. There are limited sources of conventional fuels such as coal, petroleum, nuclear, etc. which are depleting very fast in over the past few decades. A type of thermal energy storage (TES) is always recommended for proper utilization of the energy. TES helps to balance and reduce the discrepancy between demand and supply of the energy. A TES system can store all types of thermal energy available i.e. solar energy, surplus thermal energy, waste heat from plants, industries etc. Many methods are used to store thermal energy over the years. LHTES is the preferred choice because of its high energy storage desnity that further results into requirement of smaller storage size. PCM integrated TES system is essentially used in numerous applications such as storage of solar thermal energy, thermal storage in buildings, engine cooling, domestic water, space heating, etc. Storage of thermal energy is usually processed by storing either heat in form of sensible heat or latent heat. Further, LHTES is accomplished with the help of PCMs which is also helpful in nearly isothermal charging/discharging. Thus, PCMs have received considerable attention for the LHTES systems due to the following reasons:

1. Due to increase in cost of fossil fuels and greenhouse gas emission,

2. Due to their potential for TES,

3. High energy storage density,

4. The high energy content within a narrow operational range of temperature,

5. Chemically stable,

6. Non-corrosiveness, and

7. Storage of energy at almost constant temperature

When PCM exposed to hot and cold surroundings, it undergoes melting (charging process) and solidification (discharging process) respectively.[1]

\section{APPLICATIONS}

PCM integrated TES system is essentially used in many practical applications such as solar energy storage[2], diurnal storage of thermal energy in buildings for cooling and heating [3] thermal management of electronic devices [4], cooling of engines [5], heating of domestic water, and industrial applications. In the early practice, PCMs were mostly reported in the cold storage applications. This was mainly associated with the cooling arrangements inside building, food industries, refrigeration, frozen food preservation etc. Thereafter, asvancements in PCMs have been identified and promoted the use in the high temperature applications such as solar thermal energy storage, waste heat recovery, space heating, 
domestic water heating, industrial water heating, etc.

\section{EFFECT OF DESIGNS ON THE PERFORMANCE OF LHTES SYSTEM}

Several authors presented the design of the LHTES system concerning to the requirements of various applications taking care of the performance also.

\subsection{Effect of shape of a container}

El Omari et al.[6]reported the outcomes by changing the container shape on the fusion of PCM kept inside. Four geometries of same volume were selected for the comparison. Refer Figure 1 to observe different geometries selected. Paraffin wax was selected as a PCM for the investigation and nano particles were added to increase the thermal conductivity. In this study, a numerical investigation was carried out and targeted electronics cooling.

It was obtained from results that the first container had a great impact on stabilizing the temperature.

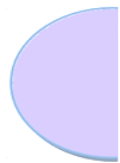

(a)

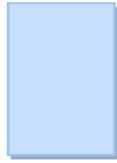

(b) (c)

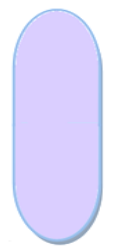

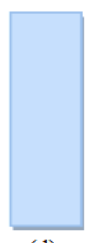

(d)
Figure 26: Different shape of containers containing PCM[6]

It was concluded that while designing a PCM container, it is helpful to provide smooth curves and avoid sharp corners to have proper melting of PCM inside.

\subsection{Effect of multi-tube on charging and discharging of LHTES}

Agyenim et al.[7]concluded from their study on Multi-tubes inside an LHTES that the time taken while charging is shorter compared to the control system as shown in Figure 2. It was reported due to increase in overall are of heat transfer with multitubes.

It was also observed that in a multi-tube system complete melting of PCM was obtained in less time as compared to the control system. The reason behind this is the multi heat transfer surfaces in multi-tube system.

\subsection{Effect of eccentricity in LHTES}

Darzi et al.[8] make the three configurations taking the two tubes

Case A: Concentric cylinders

Case B: Eccentric Centre to Centre distance $5 \mathrm{~mm}$
Case C: Eccentric Centre to Centre distance $7.5 \mathrm{~mm}$ After $20 \mathrm{~min}$, Case $\mathrm{C}$ showed proper melting whereas the other two cases observed improper melting. Hence longer melting time was observed.
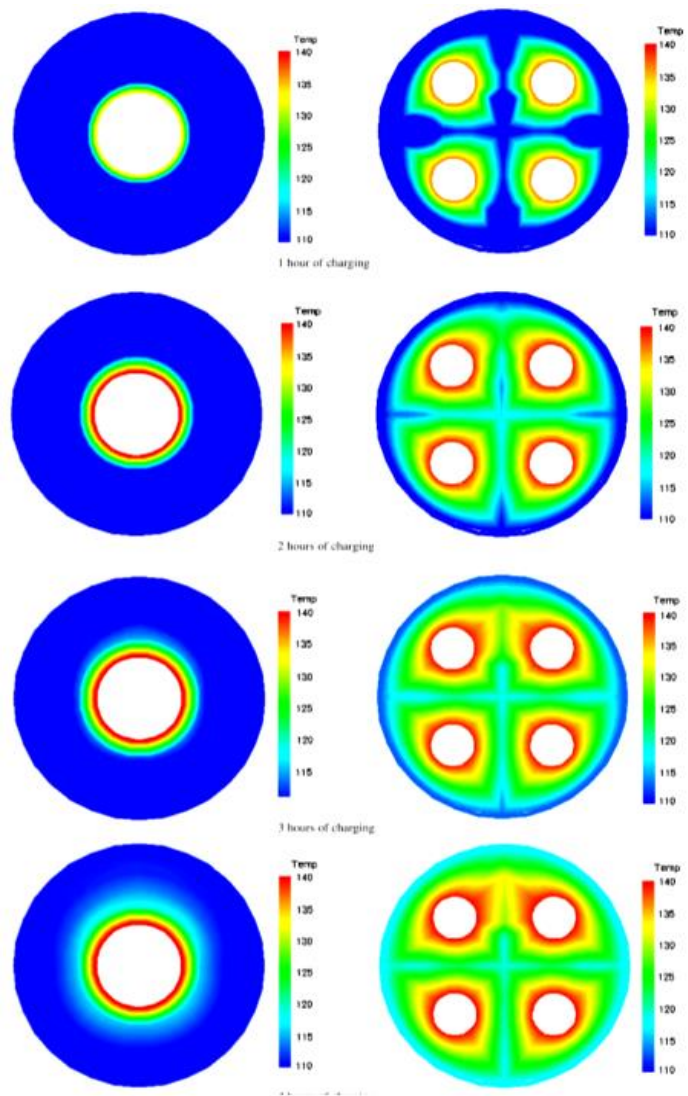

Control System

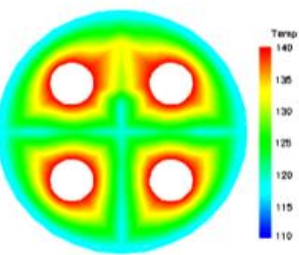

Multi-tube System

Figure 27: Melting in Control system and Multi-tube system[7]
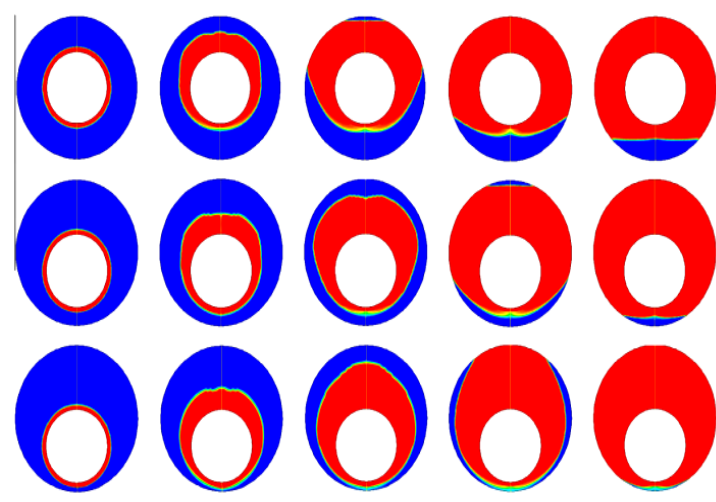

Figure 28: Melting in Concentric and Eccentric [8]

\subsection{Effect of Compactness factor in LHTES}

Tay et al.[9] experimentally investigated with the help coiled tubes in the TES system comprised of inorganic salt hydrate PCMtaking in context. The compactness factor (CF) effect was presented on 
the storage tank design. CF describes the energy storage density. Design expansions were made using the varied length of tubes. As shown in Figure 4 design (a) contained a single coiled tube of 5.46 m length (CF 98\%) and (b) contained two coiled tubes of 5.61 and $6.01 \mathrm{~m}$ in length (CF 95\%) followed by (c) contained four coiled tubes 5.79, 5.95, 6.04 and $6.05 \mathrm{~m}$ in length (CF 90\%).

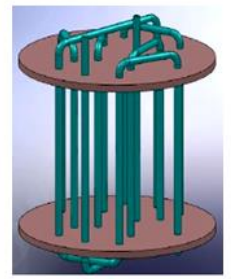

(a)

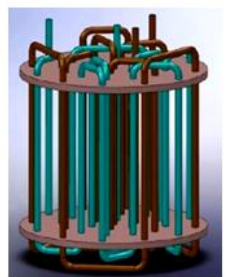

(b)

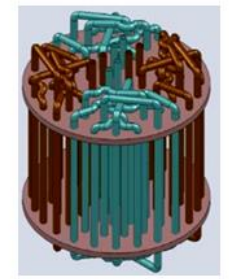

(c)
Figure 29: (a) Single coiled tube (b) Two coiled tubes (c) Four coiled tubes TES [9]

It was reported that designs (b) and (c) were more effective compared to that of design (a). Finally, it was concluded that the C.F. is directly proportional to surface area of heat transfer and act inversely with effectiveness.

In another study Tay et al. [9] focussed on the four coiled tube design which was the best design as mentioned in their earlier work to carry out the experimental study. The PCM used during the experiment was water within a tank of $330 \mathrm{~mm}$ height and $290 \mathrm{~mm}$ diameter. Heat transfer fluid (HTF) was allowed to flow through the coiled tubes. Charging and discharging were processed and obtained results so were compared with CFD analysis results. It was reported that the experimental results showed a better melting rate in comparison to simulated results. Results were comparable to those of the freezing process. The primary reason behind this was to neglect the natural convection phenomenon while simulating.

\subsection{Effect of pin fins and circular fins in LHTES}

Further, Tay et al. [10] developed three more models; the first model had a simple copper tube, the second model had the circular type fins fixed on the copper tube and the last model had the pin type fins fixed on the copper tube of length $100 \mathrm{~mm}$ with $12.7 \mathrm{~mm}$ and $9.5 \mathrm{~mm}$ outer and inner diameter respectively. The lengths of the copper tubes were as 20,30 and $40 \mathrm{~mm}$ along with diameters of 3, 5, 7 and $9.5 \mathrm{~mm}$ respectively. Results showed that in the circular type fins effectiveness was increased by 20 to $40 \%$ compared to the pinned tubes. The effectiveness increases with the number of fins around the tube. They further suggested that an effective design consists of area with high heat transfer rate along with a high CF capable of high charging and discharging rates.

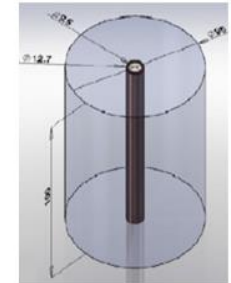

(a)

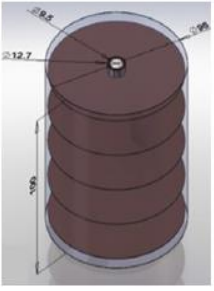

(b)

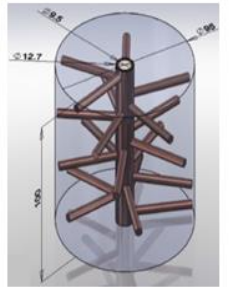

(c)

Figure 30: (a) Plane tube (b) Finned tubes and (c) Pinned tubes Thermal energy storage [10]

\subsection{Effect of circular fins and longitudinal fins in LHTES}

Erek et al. [11] used circular and longitudinal fins on a circular inner pipe to increase the rate of heat transfer. The longitudinal finned system was dominating in case of charging and while concentric tube PCM system proven ti be effective during discharging. It was reported because of these types of systems as optimal charge performance can be achieved. Also, there was a negligible subcooling observed during discharging. The low heat transfer was achieved in the case of circular fins compared to the longitudinal fins.

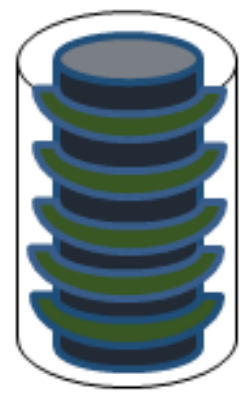

(a)

Figure 31: (a)circularand (b) Longitudinal fins[11]

Languri et al.[12]proposed a TES model consisting of panels corrugated pivoting around a tube made of copper. A high aspect ratio of 6.35 and volume to surface ratio of $506.5 \mathrm{~m}$ were considered in this design. One corrugated fin consisted of six square copper panels joined on the circular tube and similarly six fins at $60^{\circ}$ as shown in Figure 7 . The copper panels were filled with $900 \mathrm{~cm}^{3}$ of the PCM to prepare TES. The complete arrangement was kept inside a transparent plastic pipe keeping both ends closed. Water as HTF was allowed to flow through the plastic tube. Reynolds number and Stefan number were evaluated for the investigation.

PCM melting time for HTF flowing upward was decreased by $70 \%$ in compared to HTF flowing downward. Results were similar for freezing as melting. Staratification was observed when Stefan number was on the higher value. However, there was no temperature gradient observed in the axial 
direction because of conduction and convection take place on the surface of the tube. Further, it was stated that the improved design was better than a multi-tube system because of higher ratio of surface to volume in the improved TES design and also due to the HTF flow direction.

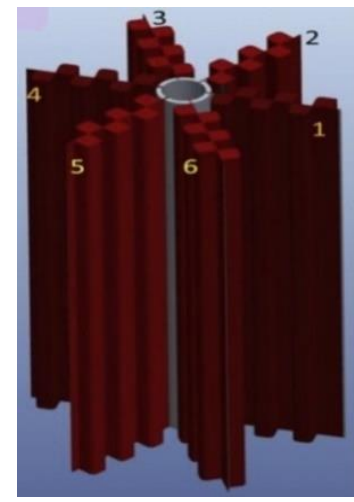

Figure 32: Corrugated TES [12]

In another study,Cárdenas and León[13]concluded from their study that while using a single PCM inside a TES would have a decreasing temperature gradient with the direction of flow of HTF. They further added that using Multi PCMs solved this issue. It was reported that if MultiPCMs are stacked together in reverse melting temperature order as shown in Figure 8 then there will be negligible temperature difference during the charging/discharging irrespective of the HTF temperature decreases/increases.

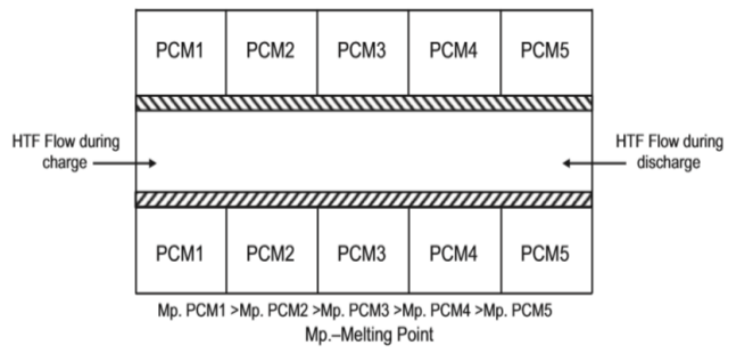

Figure 33:Multi PCMs arrangement [13]

Wang et al.[14]added into this concept through their research that Multi PCMs enhanced the heat transfer rate by keeping sufficient driving force along the direction of flow which is impossible while keeping a single PCM. However, significant research devoted to the elaboration of Multi PCMs superiority on single PCM to improve the effectiveness and efficiency of LHTES.

Kurnia et al.[15]comparing the shown designs in Figure 9, Festoon design showed enhanced heat transfer among presented designs. Also at the early stage, the melting fraction was higher in this design. This is mainly because of the increased heat transfer area among other proposed designs. Further, it was recommended that staggered fins when attached with U-tube may give better results.

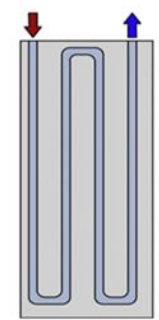

(a)

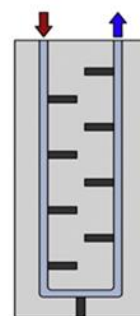

(b)

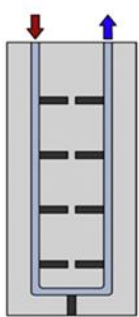

(c)

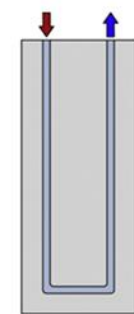

(d)
Figure 34:Different configuration of U-tube with and withou fins(a) Festoon design (b) U-Tube with staggered fins (c) UTube with in-line fins (d) U-Tube[15]

\subsection{Effect of multiple PCM arrangements}

Kurnia et al.[15]designed experimental setup using multi PCMs arranged in horizontal and vertical configurations. There were four configurations studied as shown in Figure 10 here. It was concluded that enhanced heat transfer was achieved in horizontal arrangement of the different melting point PCMs in comparison to the vertical arrangement.
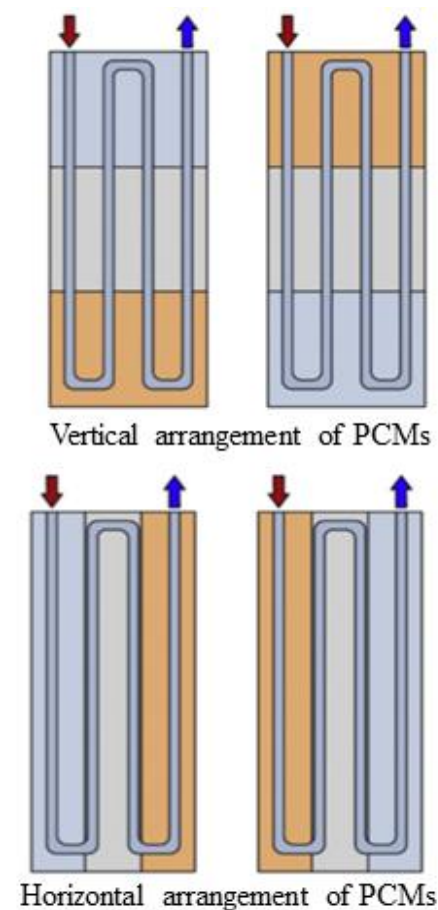

Figure 35:Different arrangements of multiple PCMs in thermal energy storage.[15]

Continuing the efforts for design modifications to offer a design that can effectively manage the energy transactions from an LHTES, Al-Abidi et al.[16] reported a three concentric tubes copper material of $500 \mathrm{~mm}$ each. This was an analytical study that was proposed to replace the double pipe heat exchanger with a triplex tube heat exchanger (TTHX) for the air-conditioning application. The 
diameter is taken for the outer, middle, and inner concentric tubes are $200 \mathrm{~mm}, 150 \mathrm{~mm}$ and $50.8 \mathrm{~mm}$ respectively. The paraffin PCM was filled inside the annular gap between the inner and middle tubes so that HTF flow could be managed inner and outer of that PCM containment to observe the different heating methods for better charging/discharging. Three different heating methods were experienced analytically to compare the PCM melting inside, keeping HTF flow inside the tube, outside tube and HTF on both sides. It is also observed that with increase in the flow rate ranging between $8 \mathrm{~kg} / \mathrm{min}$ and $32 \mathrm{~kg} / \mathrm{min}$, the melting rate was also increased but noted undesirable effects over $40 \mathrm{~kg} / \mathrm{min}$ of flow rates.

Further, it was noted that initially, due to conduction, melting of PCM initiated at the inner most surface of tube, thereafter, a skinny film of liquid was observed inside the tube. With the increase in melting of PCM, quantity of liquid also increased that led to significant role of buoyancy forces and natural convention in this process. This resulted into enhance heat transfer rate.

Like previous cases, outside heating was deployed and observed the same thing happened with the outer surface of the tube. The melting fraction of one was achieved in the $2^{\text {nd }}$ and $3^{\text {rd }}$ modes of arrangement. It was concluded that there was a negligible variation in axial temperature in all three modes. However, temperature gradient was observed between the inner wall of tube and outer surface and reported through the analysis of the profile of radial temperatures.

Mat et al.[17]proposed a 2D model of various design configurations of TTHX to understand the heat transfer. The analytical results favored case $\mathrm{F}$ concering to the time taken to achieve melting fraction of PCM as one. $34.7 \%$ reduction was observed in the melting time compared to Case A. Case $\mathrm{F}$ having the 8 segment to fill the PCM which increase the heat transfer area between HTF and PCM. The fin thickness effect was insignificant compared to the number of fins and also with the length of fins.

Al-Abidi et al.[18] further added modifications in the existing design by placing fins both sides (i.e. inner and outer) in TTHX to improve the heat transfer as compare to the triplex tube without fins, triplex tube with internal fins and triplex tube with external fins. Heat transfer area was further increased by placing PCM in between the inner tube and outer tube of TTHX. This was proven helpful as it allowed the flow of HTF both the sides of PCM and resulting lower thickness of heat quenching. Pipes made of $\mathrm{Cu}$ were used for high thermal conductivity.
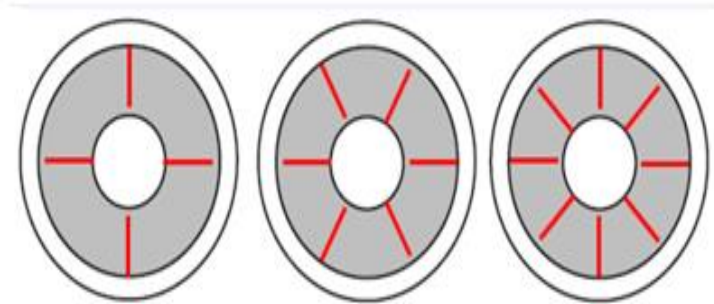

Case A

Case B

Case C

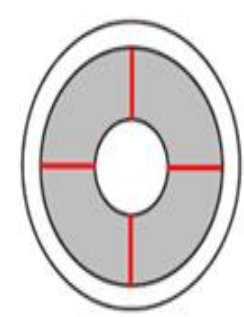

Case D

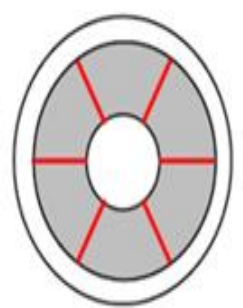

Case E

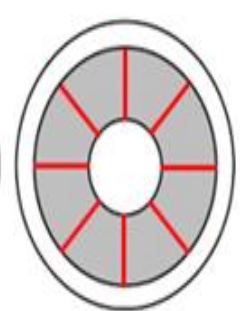

Case $\mathrm{F}$

Figure 36:Different cases in TTHX[17]

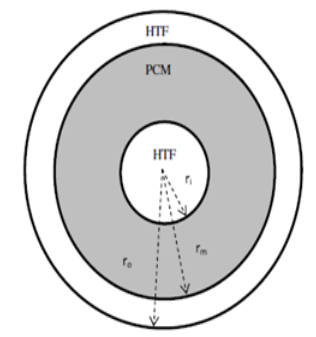

Triplex Tube without fins

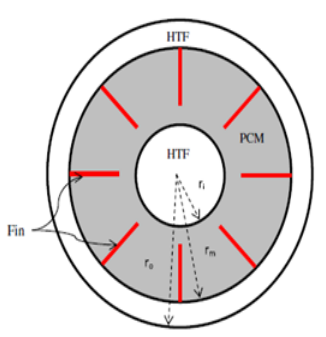

Triplex Tube with external fins

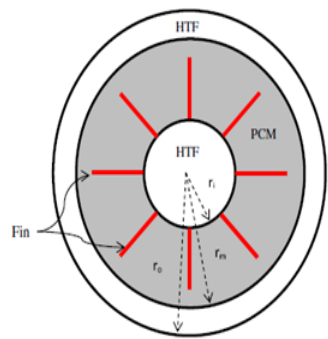

Triplex Tube with internal fins

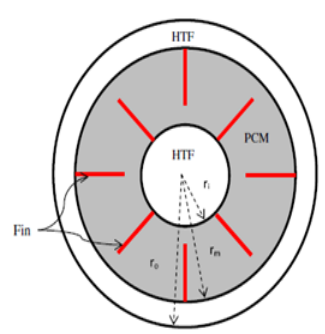

Triplex Tube with internal-external fins
Figure 37:Different arrangements of fins in TTHX[18]

\section{CONCLUSIONS}

The LHTES system gives high energy storage capacity and effective charging/discharging. An effective design of LHTES promotes the efficient and effective melting and freezing of the PCMs. Sharp corners restrict the heat release and restore from PCMs. Therefore, it is essential to avoid sharp corners while designing LHTES. In addition to this, the multi-tube arrangement inside is also helpful to enhance heat transfer by offering large surface area. Triplex tube arrangement has proven to be helpful to increase the rate of heat transfer within an LHTES. This helps by reducing distance of heat quenching inside. 
Understanding heat transfer within is essential for design modifications of LHTES. It is reported that heat transfer within an LHTES is primarily conduction dominated and thus slow as PCMs are having low thermal conductivity. Literature further detailed that improvement in design for convection dominated helped to achieve a btter heat transfer within an LHTES. Thus many designs such as eccentric tube position of inner tube, longitudinal fins, and Multi PCM had proven effective. The enhanced rate of charging/discharging was furtehr achieved by using pins and different types of extended surfaces because of increase in surface area.

Furthermore, TTHX design showed better performance in the analytical results. Keeping PCM in compartments and observing both side flow case improves the heat transfer from TTHX. Hence it is concluded that the design of LHTES always needs proper design of heat exchanger inside for better performance.

\section{REFERENCES}

[1] S. M. Hasnain, "Review on sustainable thermal energy storage technologies, part I: Heat storage materials and techniques," Energy Convers. Manag., vol. 39, no. 11, pp. 1127-1138, 1998.

[2] M. Kamimoto, Y. Abe, S. Sawata, T. Tani, and T. Ozawa, "Latent thermal storage unit using form-stable high density polyethylene; part II: Performance of the storage unit," J. Sol. Energy Eng. Trans. ASME, vol. 108, no. 4, pp. 282-289, 1986, doi: 10.1115/1.3268107.

[3] M. Koschenz and B. Lehmann, "Development of a thermally activated ceiling panel with PCM for application in lightweight and retrofitted buildings," Energy Build., vol. 36, no. 6, pp. 567-578, 2004, doi: 10.1016/j.enbuild.2004.01.029.

[4] L. F. Cabeza, H. Mehling, S. Hiebler, and F. Ziegler, "Heat transfer enhancement in water when used as PCM in thermal energy storage," Appl. Therm. Eng., vol. 22, no. 10 , pp. 1141-1151, 2002, doi: 10.1016/S13594311(02)00035-2.

[5] D. Pal and Y. Joshi, "Application of phase change materials for passive thermal control of plastic quad flat packages: A computational study," Numer. Heat Transf. Part A Appl., vol. 30, no. 1, pp. 19-34, 1996, doi: 10.1080/10407789608913826.

[6] K. El Omari, T. Kousksou, and Y. Le Guer, "Impact of shape of container on natural convection and melting inside enclosures used for passive cooling of electronic devices," Appl. Therm. Eng., vol. 31, no. 14-15, pp. 3022-3035, 2011 10.1016/j.applthermaleng.2011.05.036

[7] F. Agyenim, P. Eames, and M. Smyth, "Heat transfer enhancement in medium temperature thermal energy storage system using a multitube heat transfer array," Renew. Energy, vol. 35, no. 1, pp. 198-207, 2010, doi 10.1016/j.renene.2009.03.010.

[8] A. A. R. Darzi, M. Farhadi, and K. Sedighi, "Numerical study of melting inside concentric and eccentric horizontal annulus," Appl. Math. Model., vol. 36, no. 9, pp. 4080-4086, 2012, doi: 10.1016/j.apm.2011.11.033.

[9] N. H. S. Tay, F. Bruno, and M. Belusko, "Experimental validation of a CFD model for tubes in a phase change thermal energy storage system," Int. J. Heat Mass Transf., vol. 55, no. 4, pp. 574-585, 2012, doi: 10.1016/j.ijheatmasstransfer.2011.10.054

[10] N. H. S. Tay, F. Bruno, and M. Belusko, "Comparison of pinned and finned tubes in a phase change therma energy storage system using CFD," Appl. Energy, vol. 104, pp. 79-86, 2013, doi: 10.1016/j.apenergy.2012.10.040.

[11] A. Erek, Z. Ilken, and M. A. Acar, "Experimental and numerical investigation of thermal energy storage with a finned tube,” Int. J. Energy Res., vol. 29, no. 4, pp. 283301, 2005, doi: 10.1002/er.1057.

[12] E. M. Languri, C. O. Aigbotsua, and J. L. Alvarado, "Latent thermal energy storage system using phase change material in corrugated enclosures," Appl. Therm. Eng., vol. 50, no. 1, pp. 1008-1014, 2013, doi 10.1016/j.applthermaleng.2012.07.012.

[13] B. Cárdenas and N. León, "High temperature latent heat thermal energy storage: Phase change materials, design considerations and performance enhancement techniques," Renew. Sustain. Energy Rev., vol. 27, pp. 724-737, 2013, doi: 10.1016/j.rser.2013.07.028.

[14] J. Wang, G. Chen, and F. Zheng, "Study on phase change temperature distributions of composite PCMs in thermal energy storage systems," Int. J. Energy Res., vol. 23, no. 4, pp. 277-285, 1999, doi: 10.1002/(SICI)1099-114X(19990325)23:4<277::AIDER475>3.0.CO;2-Q.

[15] J. C. Kurnia, A. P. Sasmito, S. V. Jangam, and A. S Mujumdar, "Improved design for heat transfer performance of a novel phase change material (PCM) thermal energy storage (TES)," Appl. Therm. Eng., vol. 50, no. 1 , pp. 896-907, 2013, doi: 10.1016/j.applthermaleng.2012.08.015.

[16] A. A. Al-Abidi, S. Mat, K. Sopian, M. Y. Sulaiman, and A. T. Mohammad, "Experimental study of PCM melting in triplex tube thermal energy storage for liquid desiccant air conditioning system," Energy Build., vol. 60, pp. 270-279, 2013, doi: 10.1016/j.enbuild.2013.01.031

[17] S. Mat, A. A. Al-Abidi, K. Sopian, M. Y. Sulaiman, and A. T. Mohammad, "Enhance heat transfer for PCM melting in triplex tube with internal-external fins," Energy Convers. Manag., vol. 74, pp. 223-236, 2013, doi: 10.1016/j.enconman.2013.05.003.

[18] A. A. Al-Abidi, S. Mat, K. Sopian, M. Y. Sulaiman, and A. T. Mohammad, "Internal and external fin heat transfer enhancement technique for latent heat thermal energy storage in triplex tube heat exchangers," Appl. Therm. Eng., vol. 53, no. 1, pp. 147-156, 2013, doi: 10.1016/j.applthermaleng.2013.01.011. 